\title{
O AUTOCULTIVO E A EDUCAÇÃO DA SENSIBILIDADE NA PEDAGOGIA WALDORF
}

\author{
SELF-CULTIVATION AND THE EDUCATION OF SENSIBILITY IN WALDORF \\ PEDAGOGY
}

Jonas Bach Junior Pós-Doutor em Educação (Unicamp), Universidade Federal do Triângulo Mineiro - UFTM Uberaba, Minas Gerais - Brasil jonas.bach@uftm.edu.br

Resumo: Este artigo discute o papel que a experiência estética e a sensibilidade humana possuem dentro dos parâmetros educacionais da Pedagogia Waldorf, a partir da abordagem da filosofia da educação. A quebra de paradigma ocorre na ênfase e valorização da experiência humana, como fonte de vivências que enriquecem o mundo de sensações e sentimentos para dar suporte à vida cognitiva do ser humano. Steiner se inspirou na fenomenologia de Goethe para fundar sua concepção de educação e valorizou o desenvolvimento da sensibilidade como ideal para a formação humana (Bildung). A educação da sensibilidade é um fator importante tanto no autocultivo (Selbstbildung) dos professores, quanto na educação das crianças e jovens. O elemento chave na compreensão da educação estética não reside no que se ensina, mas no como.

Palavras-chave: Bildung. Educação estética. Goethe. Pedagogia Waldorf.

\begin{abstract}
This article discusses the role that aesthetic experience and human sensitivity play within the educational parameters of Waldorf Education, from the approach of the philosophy of education. The paradigm break occurs in the emphasis and valorization of human experience, as a source of experiences that enrich the world of sensations and feelings to support the human being's cognitive life. Steiner was inspired by Goethe's phenomenology to found his conception of education and valued the development of sensibility as ideal for human formation (Bildung). Sensitibility education is an important factor both in the self-cultivation (Selbstbildung) of teachers and in the education of children and young people. The key element in understanding aesthetic education is not what is taught, but how.
\end{abstract}

Keywords: Bildung. Aesthetic education. Goethe. Waldorf pedagogy.

\section{Para citar - (ABNT NBR 6023:2018)}

BACH JUNIOR, Jonas. O autocultivo e a educação da sensibilidade na pedagogia waldorf. Eccos - Revista Cientifica, São Paulo, n. 53, p. 1-16, e16638, abr./jun. 2020. Disponível em: https://doi.org/10.5585/eccos.n53.16638. 
A tradição pedagógica possui parâmetros claros do que significa em sua práxis o estímulo e fomento do desenvolvimento intelectual humano. Metodologias de ensino, didática, sistema de avaliação e currículos foram configurados ao longo do tempo para atender a demanda da ciência e da cultura civilizatória europeia, ou seja, os desdobramentos do intelecto como capacidade humana para explorar e dominar a natureza. Sob a orientação do utilitarismo como referência criadora de valores na era da industrialização, a educação nos séculos XIX e XX vai incorporando os ditames de que só possui valor o que é útil. Nesse sentido, o desenvolvimento cognitivo absorve a atenção pedagógica relegando a planos secundários outras faculdades humanas como a imaginação, a sensibilidade, o senso estético, a expressão artística, etc. Disciplinas de cunho artístico ou de atividades corporais parecem adereços complementares, com funções "úteis" de "relaxamento", diante dos esforços mentais exigidos diante do que realmente "importa": o domínio do raciocínio lógico, a incorporação das regras do vernáculo linguístico, e enfim, as habilidades nas disciplinas exatas como a matemática ou vinculadas às ciências naturais.

A proporção da distribuição entre as disciplinas úteis (língua portuguesa, matemática, ciências...) e as disciplinas "adereço" (artes em geral, educação física, ...) - tanto no currículo em geral quanto na grade horária - é significativa e explicitamente favorável às primeiras em detrimento das segundas. Além disso, as disciplinas úteis e complementares parecem dois mundos paralelos, intangíveis entre si, um voltado para a razão, o outro voltado para a distração (racional e irracional). Como o sistema educacional é previsível na transição entre a educação básica e a educação superior, impondo um sistema de seleção ao ingresso da fase preparatória ao futuro mundo do mercado de trabalho, sabe-se de antemão que o sucesso já possui prérequisitos claros: passa para a educação superior os que possuem melhor desempenho em faculdades cognitivas específicas. Assim, os representantes das tais disciplinas "adereço" são obrigados a criar um discurso defensivo e justificador para a inclusão de suas disciplinas em "brechas" curriculares e nas grades horárias.

$\mathrm{Na}$ atualidade, devido às expectativas concretas no investimento da presença da arte na educação, há pesquisas que almejam reconhecer os efeitos internos e externos das experiências estéticas e das atividades artísticas. Para encontrar justificativa, apela-se inclusive à possibilidade do desenvolvimento de habilidades não artísticas através da arte. "Essas expectativas muito amplas em relação aos efeitos educacionais da estética incluem a suposição de que através de atividades artísticas também são adquiridas habilidades não artísticas" (RITTELMEYER, 2006, p.32) ${ }^{1}$. Quanto mais próxima a vida estudantil está no processo seletivo para o ingresso em faculdades e universidades, mais exígua é a chance de atividades 
artísticas e corporais encontrarem seu espaço. O caso é bem diferente quando se trata da educação infantil, onde ainda permanece mais aberto o espaço de inserção daquilo que não evidencia diretamente sua utilidade.

\section{Outro paradigma}

A Pedagogia Waldorf baseia-se num paradigma completamente diferente. O desenvolvimento cognitivo é tão importante quanto o desenvolvimento dos sentimentos e da sensibilidade. Isso não quer dizer que a importância de ambos seja idêntica, mas sim equivalentes, ou seja, a potencialização dos sentimentos e da sensibilidade no espaço escolar possui contribuições tão significativas para o devir humano quanto a potencialização da intelecção humana.

Esse critério pedagógico assumido pelos educadores Waldorf possui sua fonte de origem no legado cultural e científico de Johann Wolfgang von Goethe (1749-1832), que posteriormente foi ampliado e aprofundado pelo filósofo austríaco Rudolf Steiner (1861-1925), que fundou a Pedagogia Waldorf em 1919.

Comumente Goethe é reconhecido como referência no âmbito artístico-literário, pois foi poeta e escritor, inaugurador do romance de formação (Bildungsroman), além de ícone do movimento literário Tempestade e Ímpeto (Sturm und Drang). O mesmo patamar de reconhecimento público, porém, não foi alcançado em suas obras científicas, cujo destaque principal se concentra na área biológica (na sua obra A Metamorfose das Plantas) e na área da física (com sua Doutrina das Cores), cujo teor epistemológico provoca intenso choque paradigmático com as prerrogativas da ciência vigente (leia-se: o paradigma da física clássica de Isaac Newton). A consciência das questões dos paradigmas científicos surgiu como debate amplo somente no século XX com a problematização de Thomas Kuhn (1922-1996) em seu livro A Estrutura das Revoluções Científicas (KUHN, 1998). A ciência realizada por Goethe pressupõe outra postura investigativa diante da natureza, exigindo do pesquisador a assunção de outro parâmetro paradigmático. Esse diferencial paradigmático goethiano foi reconhecido por Steiner como modo de fazer ciência que se adiantou em relação à ciência dos séculos XVIII e XIX, e que não foi compreendido então. As obras científicas de Goethe tiveram que esperar quase dois séculos para começarem a ser reconhecidas como uma fenomenologia da natureza (BACH JR., 2019).

Existe um fio condutor que parte da fenomenologia e da arte de Goethe e chega à configuração dos procedimentos pedagógicos da educação Waldorf. Goethe como pesquisador 
da natureza entra em embate com a ciência de seu tempo. Ele não abre mão da experiência dos sentidos, do que o corpo proporciona em termos de sensações e impressões, ocasionando um mundo de sentimentos e emoções. Num primeiro momento, o que se torna conteúdo da interioridade humana passa pelos sentidos, esse conteúdo pode ser elaborado posteriormente pelo intelecto. Se na ciência de Goethe a sensibilidade humana foi um campo de aperfeiçoamento para a participação do todo do ente humano na sua interação com a natureza, no campo da arte a ênfase à sensibilidade humana ganhou igual importância.

O homem não é apenas um ser pensante, mas também alguém que sente. Ele é um todo, uma unidade de forças múltiplas intimamente associadas. A obra de arte deve a falar a este todo do homem, corresponder a essa rica unidade, a essa multiplicidade que nele existe (GOETHE, 2005, p.11).

Porém, a ciência direcionou o desenvolvimento humano excluindo a sensibilidade. A ciência moderna rompe com dois aspectos primordiais do contato humano com a realidade. Através de Bacon, a riqueza, a diversidade e contingências das experiências humanas são substituídas pelos procedimentos controlados do experimento. A experimentação como modus operandi expulsa o papel de autoridade que a experiência delegava, na Antiguidade e na Idade Média, à vivência dos sujeitos, aos mais velhos, à tradição, aos sacerdotes. A experiência pressupõe a contingência da vivência, sua imprevisibilidade, sua espontaneidade, permitindo o acúmulo privilegiado de um saber obtido por dedução no decurso do tempo vivido, por uma coletividade ou por um indivíduo. A experimentação inverte os princípios anteriores, extrapola a contingência e busca a lei, o que é válido independentemente do espaço, do tempo e do sujeito. Para isso, artificializa as condições imprescindíveis para a manifestação de determinado fenômeno. Cria hipóteses que precisam ser verificadas e constatadas, repete os experimentos controladamente, descarta os fenômenos que não se enquadram no critério hipotético empirista. Outra faceta da ciência moderna é a corrente do racionalismo, imputando ao corpo, ou seja, ao ser que fornece a experiência sensorial e estética, a culpa do erro. Seguindo a tradição platônica - o corpo é o cárcere da alma - e seu desdobramento na patrística medieva em Santo Agostinho - o corpo é fonte de pecado - Descartes funda a variante moderna: o corpo é fonte de erro. A educação convencional absorveu esses princípios que erigiram a ciência moderna e que configuraram o pensamento pedagógico tradicional.

A experiência humana, base fundante da fenomenologia de Goethe, torna-se através de Steiner (2004) - aliada à influência que este teve de Friedrich Schiller (1759-1805) - o vórtice do dinamismo pedagógico: o sujeito aprendiz se conecta ao mundo através de suas experiências. Assim, a Pedagogia Waldorf valoriza a experiência estética na escola, na sala de aula, tanto para funções de refinamento da sensibilidade humana, quanto para funções de saltos de 
apreensão intelectiva da realidade, que pode culminar em conhecimento científico. A educação cognitiva é acompanhada da educação dos sentidos, das sensações, dos sentimentos, da educação estética enfim. Essa é uma das razões para as "reações de estranhamento" quando o senso comum aborda a Pedagogia Waldorf, sem conhecer seus fundamentos, pressupostos e objetivos. As descrições dos procedimentos pedagógicos numa escola Waldorf deixam claro que o tempo dedicado à memorização, ao raciocínio lógico, à análise, ao conteúdo teórico, é compartilhado com inúmeras vivências artísticas, com experiências diretas da natureza e de diversos fenômenos, com o fomento da imaginação e da inventividade, para que processos sejam vivenciados (STOCKMEYER, 2015). O objetivo de tudo isso é permitir ao sujeito da experiência, o sujeito aprendiz, o estudante Waldorf, a leitura do vivido, a leitura de mundo, a leitura da sua experiência. Isso tudo implica na inclusão da contingência, do que acontece hic et nunc, no aqui e agora, no espaço e no tempo. E a contingência valoriza o corpo humano e seus órgãos sensoriais, a alma humana e a interiorização em sensações e sentimentos dos conteúdos vivenciados, o espírito humano e a ampliação da consciência (AVISON; RAWSON, 2016). Mas a contingência como fator humano foi expulsa da ciência e, mais tarde, banida das prioridades da educação convencional.

Nesse sentido, a Pedagogia Waldorf nada contra a corrente, ela foge a todos os convencionalismos e lugares-comuns, possui outra lógica e entendimento do desenvolvimento humano e das necessidades humanas, não abrindo mão da educação estética. Os sentimentos, as sensações podem ser abordados em sua qualidade primeira, como mera manifestação reativa do ser humano diante das impressões sensoriais fornecidas pelo corpo. Mas o caráter reativo é meramente um primeiro plano, há ainda a possibilidade de intervenção e transformação da interioridade. A valorização da sensibilidade humana diz respeito ao papel da educação como atividade transformadora e direcionadora da interioridade humana. A educação estética na Pedagogia Waldorf é compreendida como base de expansão da consciência, como atividade de refinamento e sensibilização da interioridade, aliada ao desenvolvimento da cognição. Esse critério pedagógico visa a formação do ser humano como um todo (GUERRA, 2019). Em outras palavras, a concepção de educação de Steiner se insere na perspectiva da Bildung - a formação humana - como projeto educativo tencionando a vida em suas diversas facetas e dimensões. Nesse sentido, é necessário revisar o entendimento de Bildung e passar a compreender como Steiner configurou seu conceito de formação humana na Pedagogia Waldorf. 


\section{Pedagogia Waldorf: a Bildung steineriana}

O debate sobre a atualidade da Bildung destaca a importância de três dimensões da educação no seu papel como atividade formadora do humano: o conhecimento, a estética e a ética, ou seja, a intervenção humana a partir de suas três forças constituintes, como ser que constrói saberes, como ser de sensibilidade estética e como ser transformador do mundo. $\mathrm{O}$ debate precisa ser atualizado, inclusive para não se esquecer da "vinculação da formação às vicissitudes da vida humana, promovendo uma reflexão crítica às falsas promessas de uma educação totalmente programada ou reduzida em seu sentido econômico ou burocrático, funcional” (DALBOSCO; MÜHL; FLICKINGER; 2019, p.8). De um lado, distanciado dos ideais da Bildung, há um discurso pragmático sobre a educação, destacando-lhe somente os aspectos úteis e referendando expectativas de servilismo ao mercado de trabalho. Do outro lado, há pensadores imbuídos de ressaltar o papel de elevação das capacidades humanas frente aos desafios de seu tempo, elencando a formação humana como sentido amplo e profundo de contemplar o vir a ser humano.

Segundo Goergen (2019, p.17-18), historicamente considerado, o conceito de Bildung possui origens nos paradigmas teológicos, metafísicos e místicos, representados por seus idealizadores, respectivamente: Mestre Eckhart (1260-1328), Paracelsus (1493-1541) e Jakob Böhme (1575-1624). Para Eckhart, a formação humana é processo de aproximação da alma que pecou à pureza celestial ou divina. Para Paracelsus, a Bildung é o desabrochar do que é latente na pessoa, suas predisposições inatas. Em Böhme, a formação humana significa "o despertar e o desenvolvimento ativo de imagens e representações internas da pessoa e entre as pessoas". Somente no século XVIII a Bildung é incorporada pelo discurso pedagógico em sua linguagem disciplinar, absorvida pelo paradigma moderno e compreendida como educação e ensino. $\mathrm{Na}$ modernidade, autonomia e emancipação são conceitos agregados à formação humana, diante do progresso tecnológico e científico, configurando as necessidades de formação do indivíduo frente às demandas de uma civilização.

A filosofia da educação de Steiner inclui aspectos da concepção de Bildung formada na atmosfera intelectual moderna, com sua ênfase no autocultivo ou autoformação e na prioridade assumida na temática da espiritualidade, que é a fonte do desenvolvimento humano e das forças internas, dentro do contexto da secularização da consciência. Como essa filosofia da educação possui sua prática em plena pós-modernidade nas escolas Waldorf, cabe problematizar na atualidade uma educação estética e da sensibilidade humana dentro de um mundo estruturado 
num sistema econômico, onde a sensibilidade é cooptada e conduzida pelos mecanismos de padronização dos gostos e preferências. Pois, afinal:

\begin{abstract}
A Bildung, conforme formulada e desejada nos séculos XVIII e XIX, perdeu sua força e seu vigor num mundo totalmente administrado no qual também a consciência do homem é determinada pela ordem, pela economia, pelo sistema. A adaptação tornase não só o fim e a estratégia da educação, mas também o próprio fim e sentido do humano. De certo modo, inverte-se o fluxo das ideias que, na compreensão da Bildung, seguiam do interior para o exterior, agora, elas vêm do exterior para o interior, transformando a influência externa em polo referente e determinante da constituição do humano. Essa relação invertida transforma a consciência em falsa consciência, que reflete a realidade e perde sua prerrogativa de liberdade e autonomia. O sujeito se livra de sua responsabilidade crítica frente ao sistema, e o sistema se livra do sujeito incômodo, podendo seguir seu rumo preestabelecido. (GOERGEN, 2019, p.30)
\end{abstract}

Inspirando-se na filosofia estética de Schiller e na fenomenologia de Goethe, Steiner concebe a formação humana (Bildung) como continuidade metamorfoseada da Paideia, onde a ideia grega da arte empresta o significado dinâmico da arte da educação. Como corrobora Flickinger (2011, p.160-161), que também vê na concepção grega de arte "uma concepçãomodelo para todo o processo educativo, pois a arte de educar é idêntica à ajuda cautelosa do educador que traz à luz o potencial intrínseco ao educando, tornando-o produtivo para o contexto social." O que jaz como potencial em cada educando está ameaçado na conjuntura pós-moderna, porque a ideia de felicidade é construída como inclusão dentro de um sistema. Vidas humanas destinadas a servir sistemas têm por resultado a falta de sentido. A base fundadora de vínculo do ser humano com o mundo é o repertório de suas experiências do mundo. No entanto, em condições pós-modernas o ser humano vem sendo expropriado da experiência já na infância. Cabe ressaltar que a morte da experiência não ocorre somente no campo científico, ela domina o espaço social e as tendências civilizatórias. O empobrecimento da experiência humana anda lado a lado com o progresso tecnológico e científico.

Agamben (2005) elenca uma série de considerações para evidenciar o que ele denomina de paulatina morte da experiência no processo histórico civilizatório. Isso impacta a infância moderna como fase de vida dos indivíduos propensa e aberta à riqueza da experiência. $\mathrm{O}$ autor resgata o princípio da Antiguidade, onde não havia a dicotomia entre o sujeito empírico - a pessoa no seu espaço e tempo e que tem a experiência do seu entorno - e o sujeito transcendental ou cognitivo. A ciência moderna, ao privilegiar o experimento e excluir a experiência, fez com que esta perdesse seu papel de fonte de certeza. Na modernidade a certeza da verdade foi posta fora do homem: nos instrumentos e aparelhos mensuradores - em vez de se assegurar na percepção humana - e nos números ou na linguagem numérica, no lugar da linguagem simbólica ancestralmente adotada. A humanidade que havia colecionado ao longo dos milênios máximas 
e provérbios pautados na autoridade das gerações anteriores, assiste ao nascimento dos slogans, os provérbios de pessoas que perderam a riqueza da experiência. Baitello (2017) realiza outra problematização pertinente à questão do empobrecimento da experiência humana, ao destacar a preponderância de uma vida sentada, sedada, que trocou a experiência tridimensional in loco e de corpo inteiro e em movimento, por experiências mediadas em "janelas" bidimensionais as telas de TV, computador, celular - com o corpo parado, sendo apenas solicitado por estímulos áudio-visuais que são reprodução técnica da realidade.

A experiência primordial humana era o encontro no limite de separação entre a dimensão humana e a dimensão divina. Para explorar e dominar a natureza, a ciência moderna preconiza os modelos abstratos da realidade e distancia, assim, o ser humano de seus atos vinculantes ao mundo natural. No entanto, na educação, a criança como ser de linguagem explora o mundo externo e interno, vai aprendendo a ler suas experiências na medida em que conquista expansões do seu universo vocabular e conceitual. A criança como ser de expressão de múltiplas linguagens é um aspecto valorizado na Pedagogia Waldorf, que pauta em seus procedimentos pedagógicos a diversidade de possibilidades de acessos simbólicos que a criança realiza no seu contato com a realidade. Na prática pedagógica, isso se evidencia na abertura e fomento às expressões imagéticas nas atividades artísticas que permeiam toda a vida escolar dos estudantes Waldorf. A concepção de criança, como ser ativo no seu intercâmbio com o mundo interior e exterior, constata que "as ações e as falas infantis jamais são naturais ou destituídas de sentidos, mas são organizadas a partir das suas vivências em diferentes contextos e de acordo com suas experiências na sociedade e na cultura" (GOMES; AQUINO, 2019, p.11).

O potencial inerente a cada ser humano precisa ser estimulado e desenvolvido. As experiências não são o termo final, mas tão somente o ponto de partida. Na linguagem de Steiner, o corpo é o aparato que fornece impressões, graças a ele o mundo exterior pode ser captado e transformado em dados, porém, isso é pouco. A alma, ou o mundo da interioridade humana, colhe as impressões (os dados sensoriais) e as vive em si como sensações, emoções; enquanto o espírito humano elabora esses conteúdos interiorizados e quer transformar o mundo. Nesse encontro do ser humano com suas experiências, há o ensejo para sua autoformação.

Tanto em seu exercício como cientista, quanto em seu exercício como artista, Goethe pressupunha um processo de autoconstituição de si mesmo, à medida que intensificava suas potencialidades, tanto no domínio de suas forças internas quanto em suas relações exteriores. O seu modo de fazer ciência, que ainda permanece uma incógnita paradigmática para a atualidade, traduziu-se numa fenomenologia da natureza que exige uma postura participativa do pesquisador, "o aprimoramento disciplinado e autotransformativo do sujeito", ou seja, o 
compromisso da formação de si. "Entre as observações sensoriais, que revelam a multiplicidade do fenômeno natural, e a elaboração conceitual que desenvolve o poder das conexões (unidade), o sujeito fenomenológico realiza a intensificação da sua atividade cognitiva" (BACH JR., 2019, p.194). Em outras palavras, a fenomenologia de Goethe não se restringe a uma elaboração intelectual da experiência humana, pelo contrário, ela agrega a necessidade de uma elaboração e aprimoramento da vida sensível. As capacidades humanas a serem inauguradas dentro de um processo de autoeducação envolvem a necessidade de um refinamento das percepções humanas, que podem ser elevadas e refinadas a partir de um posicionamento deliberado do sujeito em seu autoaprimorar-se.

\begin{abstract}
A fenomenologia da natureza é um trabalho de autoformação [Selbstbildung] com o objetivo de intensificar a qualidade das percepções e potencializar as capacidades latentes da consciência para novos níveis de apreensão da realidade. Steiner apropriou-se da positividade goethiana frente ao desenvolvimento cognitivo. A autoeducação é o processo de aquisição de novas habilidades, de inauguração de novas capacidades. (BACH JR., 2019, p.182)
\end{abstract}

Em suas obras literárias, Goethe também deixou indícios de sua cosmovisão unitária da realidade, onde o sujeito cognoscente permanece com seu papel de coconfiguração [Mitgestaltung] da percepção e compreensão do mundo. Marangon (2018) destaca a peculiaridade de Goethe em reunir numa só concepção de mundo os princípios do Romantismo e do Iluminismo, tornando bem abrangente e profundo o conceito de formação humana. O ideal de educação em Goethe não se manifesta através de um discurso filosófico ou pedagógico, mas de modo indireto através das mensagens revestidas em romances e poesias, onde "cada personagem trilha seu próprio caminho formativo. Para ele, o homem se educa à medida em que toma forma particular, se determina, se limita e assim dá consistência a sua personalidade" (MARANGON, 2018, p.188). A formação humana não é algo que possa ser padronizado, ela é questão do encontro entre o indivíduo e sua interação com o outro: o pesquisador e a natureza, o leitor e a obra, o sujeito e o seu destino. Esse é o sentido resgatado por Steiner em sua filosofia da educação. A experiência humana é a força catalisadora para a autoeducação, é a energia inicial para dar dinamismo às potencialidades de aprendizado subjacentes a cada um de nós, e que se realizam de modo único e singular, porque cada ser humano é fonte de uma força autoconstituidora de sua interioridade (personalidade, o eu) e autoconfiguradora de seus intercâmbios com a exterioridade (as relações).

Steiner apreende a perspectiva de Goethe de que o ser humano não está acabado e não há termo final em sua escalada evolutiva espiritual. Os sentidos de percepção não estão prontos, podem e precisam ser aperfeiçoados assim como a inteligência. Na linguagem de Goethe, essa 
formação permanente dos sentidos e da inteligência é expressa no desenvolvimento de órgãos de percepção, tanto no sentido de aperfeiçoamento da visão, audição e assim por diante, quanto no sentido de ampliação do percebido através de novas capacidades de compreensão. Em seu romance Os Anos de Aprendizado de Wilhelm Meister, Goethe (1994, p.412-414) apresenta essas ideias nas falas do personagem Abade. Primeiro, em uma crítica a um sentido naturalista da percepção humana diante de uma obra de arte: “[...] os homens creem que os órgãos com que se desfruta uma obra de arte formaram-se por si mesmos, [...] se julga uma obra de arte como se julga uma comida". Segundo, na falta de entendimento de que há outra maneira de abordar a arte, de que é necessária outra cultura: "Não compreendem que se carece de outra cultura para se elevar até à verdadeira fruição artística”. Terceiro, Goethe aborda a força motriz da singularidade humana que espera a ocasião ou as circunstâncias internas propícias para sua manifestação, para cultivar-se: "O mais difícil, penso eu, é essa espécie de distinção que o homem deve deixar agir dentro de si, caso queira mesmo cultivar-se". O quarto aspecto, "[...] aspirando o homem a uma atividade múltipla ou a uma fruição múltipla, tem que ser também capaz de desenvolver órgãos múltiplos, independentes uns dos outros”, evidencia o desafio humano frente à diversidade e multiplicidade de suas experiências. A filosofia da educação de Steiner absorve essa problematização do atuar humano frente às possibilidades de educar para a ampliação das capacidades perceptivas, aliando estética e cognição, para a elevação do papel humano no mundo através do sublime como cultura, para abrir espaço ao sujeito como fonte de singularidade em seu cultivar-se, para fundamentar a educação nos valores da multiplicidade da experiência e na diversidade da intersubjetividade, para tornar a diversidade o contraponto do cultivar-se, como força de singularidade e que configura a unidade do sujeito.

\section{Autocultivo como educação de si próprio}

Goethe configurou suas obras artísticas e científicas tendo como base um processo cotidiano de observação e leituras das suas experiências de vida. Ou seja, a base fundamentadora do conteúdo a ser analisado, verificado e elaborado foi a sua própria biografia. O segredo biográfico de Goethe foi sua capacidade de se desviar da possibilidade de declínio diante do cotidiano, alerta este realizado bem mais tarde por Heidegger (2005, p.227-235), ao provocar o pensamento ocidental frente ao perigo do ser-no-mundo [In-der-Welt-Sein], que ao não transformar em sabedoria sua experiência cotidiana de vida, insere-se em diversas modalidades de alienação - provocadas pela impessoalidade [das Man] da vida pública - a verborragia ou o falatório [Gerede], o gosto supérfluo pela novidade [Neugierigkeit] e a 
ambiguidade [Zweideutigkeit]. Goethe extrai da fonte que possui princípios de perigo - o cotidiano em condições modernas - a salvação do seu processo existencial, ao conceber a formação humana [Bildung] como autoformação, como autoeducação [Selbstbildung]. O enfoque no sujeito que se auto-observa em interação com os fenômenos naturais e sociais, para embasar suas necessidades de autotransformação, e realizar essas transformações de si tendo como ponto de partida suas próprias resoluções, é justamente a filosofia da educação de Steiner. Os fundamentos da Pedagogia Waldorf se desdobram em dois caminhos, tendo como plano de fundo [Hintergrund] o mote da autoformação humana ou da autoeducação: a autoeducação dos docentes e autoformação das crianças e jovens. Em momento algum, autoeducação e autoformação significam um sujeito mergulhado em seu solipsismo, apartado de suas interações com o mundo e preocupado em fundamentar a realidade a partir do âmbito especulativo de suas representações do mundo, que surgem meramente da inventividade fortuita e abstrata de modelos representacionais. Pelo contrário, a autoformação humana é uma atividade intercambiante com o entorno natural e social. Ela é uma atividade cujo centro gerador do inédito encontra-se na própria pessoa, a formação de si se dá em troca contínua no fluxo do viver, como e onde quer que se esteja. Então, o conceito de autoeducação de Steiner engloba as dimensões espaciais, temporais, biológicas, psíquicas, sociais e espirituais do ser humano, em recíproca interação com todas as dimensões de manifestação dos fenômenos que vem ao encontro da pessoa. A ênfase na evolução espiritual do eu humano, registrada ao longo de todas as obras de Steiner, significa inclusive a inserção dialógica do sujeito no mundo social na formação do fenômeno social primordial Eu e Tu. A potencialidade social de sua obra $A$ Filosofia da Liberdade, por exemplo, foi explorada por Traub (2019), que evidencia a dimensão de reforma social do eu no encontro com o outro, reforma esta que cabe ao núcleo autotransformador da realidade que jaz - num modo aristotélico de se expressar - como potencialidade no ser humano, mas não necessariamente como atualidade.

Goethe não nasceu fenomenólogo da natureza, ele foi se autoconstituindo como tal ao longo do seu percurso existencial. Compreender a natureza, em sua fenomenologia, significa saber dialogar com ela. O pré-requisito do diálogo é o desafio que o ser humano possui de aprender a falar a linguagem da natureza, ou seja, a hermenêutica de Goethe, processo de autodescoberta dialógica em longos processos de observação dos fenômenos naturais e de sua busca pela compreensão do fenômeno primordial [das Urphänomen] a partir de longos processos de elaboração e refinamento do seu mundo mental ou de representações. A fenomenologia da natureza pressupõe um sujeito epistemológico engajado prioritariamente na sua autotransformação, para que nesse processo de refinamento e sensibilização de suas 
próprias representações, o sujeito possa entrar em sintonia com os diversos níveis de manifestação da miríade de fenômenos que vem ao encontro do ser humano. Ser um fenomenólogo da natureza implica em intensificar suas forças cognitivas, estéticas e sua sensibilidade, para a expansão da consciência humana. A expressão do ser se dá no vir-a-ser, no devir, por isso, a práxis fenomenológica fidedigna é puro processo de aprendizado, ao longo do tempo, a partir de uma postura investigativa dialógica.

Soetebeer (2016, p.16) enfatiza que, em Goethe, aisthesis está baseada na experiência como concepção híbrida de conhecimento, onde a "percepção atua como modo de remodelação ou recomposição (Umbildung)" do conhecimento. Por um lado, a aisthesis é fundamentada na sensorialidade como contemplação sensorial (sinnliche Anschauung), o que implica num conhecimento construído por percepções em múltiplas perspectivas, que resultam na “amplificação e expansão da experiência sensorial”. Por outro lado, a aisthesis é constituída com base na elaboração pensante, onde a atividade do pensar realiza um movimento de busca e de elevação da percepção, ou num segundo sentido, no que Goethe denominava de aperçu, “como ideia imediata, que se manifesta sem as operações discursivas do pensar". O sujeito cognoscente, ao realizar sua experiência do mundo, vivencia também a experiência da diferença do eu em relação ao mundo, a qual ele busca dominar cognitivamente.

Com essa prática de pesquisa, o sujeito modela sua participação no todo do mundo. A experiência da diferença torna-se, assim, uma experiência decisiva e remodeladora no horizonte da autoeducação transformadora, que se realiza abertamente como processo interminável. Autoeducação em um contexto global perspectiva, portanto, basicamente, a totalidade aberta. (SOETEBEER, 2016, p.17) ${ }^{2}$

A experiência da diferença, da marca da subjetividade que inaugura uma singularidade, é necessária na evolução individual e social. A experiência da diferença do eu em relação ao entorno apresenta um campo de possibilidades dinâmico e inovadoramente aberto de reconexão com o todo, a partir da autoatividade do eu que se autoeduca na remodelação de si, para construir sua relação com o todo. Steiner amplia esses princípios e os metamorfoseia para o campo da educação ao fundar a Pedagogia Waldorf. O docente Waldorf é convidado a ser o agente catalisador de sua autoformação, tendo como base o vivido em todas as situações educativas e escolares, incluindo suas vivências existenciais que se manifestam nos mistérios e impasses do seu destino. Para a filosofia da educação de Steiner, no autocultivo não existe a dicotomia entre essência e existência como foi absorvido pelo discurso pedagógico. A leitura da experiência é um incentivo à conexão do sujeito que educa a si próprio, um incentivo à sua vinculação com a existência para que nesse exercício de ligação entre sujeito e mundo, paulatinamente, o sujeito possa se autoconstituir como expressão, na existência, de sua essência. 
O movimento é pendular e inclusivo. Não trabalha a lógica do ou... ou..., ou se prioriza a essência e se exclui a existência, ou se prioriza a existência em detrimento da essência. A dinâmica reflexiva, estética e volitiva do sujeito é um movimento que abrange ambas, inclui tanto as dimensões existenciais da pessoa quanto suas dimensões essenciais.

O autocultivo implica num exercício de interpretação de si, uma hermenêutica necessária à leitura de si próprio, representado por Goethe no personagem Wilhelm Meister como alguém que "vai decifrando a si mesmo, pouco a pouco, em cada experiência, sem que isso signifique que haverá um 'estar pronto', mas sim, que haverá sempre um indivíduo mais preciso quanto a leitura de si e do mundo a sua volta" (MARANGON, 2018, p.190). Se por um lado o autocultivo é uma atividade individual que intensifica a diferenciação do sujeito, permitindo que esse se autoconheça na sua distinção em relação ao universo da diversidade, por outro lado Goethe (1994, p.412) alerta para o choque entre unilateralidades culturais, onde “cada uma tem a pretensão de anular todas as outras". O contrabalanço harmonizador do núcleo diferenciador do autocultivo, frente à atmosfera de tensão do encontro entre culturas e valores que pretendem anular-se mutuamente, é a inclusão no autocultivo da necessidade de ampliar as percepções da realidade de tal modo que elas abranjam todos os lados (omnilateralidade) e de aprofundar o trabalho reflexivo para a inserção da plena diversidade de modos de compreensão da realidade (omnicompreensividade).

[...] o aprendizado do personagem Wilhelm Meister é pensado através do exercício (ação) sobre as forças internas e externas do personagem. Nesse sentido, tal formação não é simplesmente a educação ou ao processo educativo (Erziehung), é autonomia e desenvolvimento próprio (autocultivo) tendo como ponto de partida sua própria natureza, omnicompreensividade, na busca pela omnilateralidade, é Bildung. (MARANGON, 2018, p.195)

Para Steiner (1990, p.60), a omnilateralidade [Allseitigkeit] é o desenvolvimento da capacidade humana de olhar a realidade pelo maior número possível de ângulos, não somente no sentido do ver através dos olhos que captam as cores, mas também do ponto de vista epistemológico. Nesse sentido, uma grande fonte de aprendizado para a autoeducação docente é o encontro com os educandos. Assim como a fenomenologia da natureza de Goethe é a orientação para a postura investigativa do pesquisador que almeja uma interação viva com os fenômenos naturais, a fenomenologia da consciência de Steiner é a orientação para autoeducação docente - como dinâmica de autodescoberta e autotransformação - em seu fluxo de intercâmbios vivenciados na realidade cotidiana da sala de aula ou da escola, ou seja, uma interação viva com os fenômenos sociais. 
O cultivar-se, como ideia central de uma Selbstbildung, desdobrou-se em conceito central da filosofia da educação de Steiner como autoeducação. A ideia de autoeducação, enfatizada principalmente como elemento central da atividade docente, implica no papel ativo que o sujeito autoeducante possui no processo de leitura das suas experiências, na dinâmica de descobertas em sua maneira singular de experienciar o mundo externo e interno.

\section{Considerações finais}

Steiner (1998, p.33) ressalta que a perspectiva da estética de Goethe não foca a obra artística como produto, o "que" foi feito pelo artista, mas privilegia o "como", ou seja, o processo que deu ensejo ao surgimento da arte. Transpondo esse princípio à arte da (auto)educação, o desenvolvimento da sensibilidade não se deixa reduzir a formatações dos procedimentos pedagógicos. A descoberta do "como" parece encerrar-se dentro da própria dinâmica de descobertas do sujeito da experiência. Nesse sentido, a questão contemporânea de uma pesquisa da experiência descrita, narrada e analisada em primeira pessoa, aponta para a possibilidade da pesquisa docente em seu autocultivo (DEPRAZ, 2013). Se o sujeito descobre em seu processo de autocultivo o valor e o significado de suas experiências estéticas, do desenvolvimento de sua sensibilidade, o discurso em prol de atividades pedagógicas úteis perde seu sentido.

A educação como mera atividade social para a integração de indivíduos dentro de um sistema resume-se à adaptação e reprodução. O autocultivo, a formação de si como Selbstbildung opera como processo de abertura ao inusitado no cerne da própria pessoa. $\mathrm{O}$ empobrecimento da experiência solicita uma força e postura compensatórias, pois o déficit em experiências de qualidade pode conduzir ao esvaziamento da interioridade humana. $\mathrm{Na}$ concepção de Bildung de Steiner, o espaço educativo foi pensado como locus dessa compensação.

Como a valorização da experiência ressalta a problematização da contingência, cada sujeito é estimulado a revisar e analisar a qualidade de suas vivências ao longo da sua biografia existencial e profissional, para dirimir seu posicionamento em seu tempo e espaço. Se a diversidade e riqueza de experiências estéticas colaboraram na ampliação e aprofundamento da inserção do sujeito cognoscente no mundo, então há um vínculo a uma Bildung efetivada. 


\footnotetext{
${ }^{1}$ Diese sehr weitgehenden Erwartungen an die Bildungswirkungen des Ästhetischen schließen die Vermutung ein, dass durch künstlerische Tätigkeiten auch außerkünstlerische Fähigkeiten erworben werden. (RITTELMEYER, 2016, p.17) [Tradução nossa]

${ }^{2}$ Mit dieser Forschungspraxis modelliert das Subjekt seine Partizipation im Ganzen der Welt. Die Erfahrung der Differenz wird damit zu entscheidender umbildender Erfahrung im Horizont transformatorischer Selbstbildung, die sich als Prozess unabschließbar offen vollzieht. Selbstbildung im Weltzusammenhang perspektiviert demnach prinzipiell offene Ganzheit. (SOETEBEER, 2016, p.17) [Tradução nossa]
}

\section{Referências}

AGAMBEN, G. Infância e história: destruição da experiência e origem da história. Belo Horizonte: Editora UFMG; 2005.

AVISON, K.; RAWSON, M. The tasks and content of the Steiner-Waldorf curriculum. Edinburgh, Escócia: Floris Books, 2016.

BACH JR., J. Fenomenologia de Goethe e educação: a filosofia da educação de Steiner. Curitiba: Lohengrin, 2019.

BAITELLO JR., N. O pensamento sentado: sobre glúteos, cadeiras e imagens. São Leopoldo (RS): Editora Unisinos, 2017.

DALBOSCO, C.A.; MÜHL, E.H.; FLICKINGER, H.-G. (orgs). Formação humana (Bildung): despedida ou renascimento? São Paulo: Cortez Editora, 2019.

DEPRAZ, N. D'une science descriptive de l'expérience em premiere personne: pour une phénoménologie expérientielle. Studia Phaenomenologica, Romanian Society for Phenomenology, v.13, 2013. p.387-402.

FLICKINGER, H.-G. Herança e futuro do conceito de formação (Bildung). Educação \& Sociedade, Cedes/Unicamp, Campinas, v. 32, n. 114, jan-mar, 2011, p. 151-167.

GUERRA, M.G.M. Possibilidade de humanização da escola, o diálogo e a educação integral. In: BACH JR., J. (org.). A educação Waldorf no século XXI. Curitiba: Lohengrin, 2019. p.721. Disponível em: http://frs.edu.br/biblioteca/. Acesso em: 20/02/2020.

GOERGEN, P. Bildung ontem e hoje: restrições e perspectivas. In: DALBOSCO, C.A.; MÜHL, E.H.; FLICKINGER, H.-G. (Orgs). Formação humana (Bildung): despedida ou renascimento? São Paulo: Cortez Editora, 2019. p.15-34

GOETHE, J.W. von. Os anos de aprendizagem de Wilhelm Meister. São Paulo: Ensaio, 1994.

GOETHE, J.W. von. Escritos sobre arte. São Paulo: Associação Editorial Humanitas, São Paulo: Imprensa Oficial do Estado de São Paulo, 2005.

GOMES, L.O.; AQUINO, L.M.L. de. Crianças e infância na interface da socialização: questões para a educação infantil. EccoS - Revista Científica, São Paulo, n.50, e14092, jul/set. 2019. Disponível em: https://doi.org/10.5585/EccoS.n50.14092. Acesso em: 10/02/2020.

HEIDEGGER, M. Ser e tempo. Petrópolis, RJ: Vozes; Bragança Paulista, SP: Universidade São Francisco: 2005. 
KUHN, T.S. A estrutura das revoluções científicas. São Paulo: Editora Perspectiva, 1998.

MARANGON, M.L. A formação humana em Goethe na obra: Os Anos de Aprendizagem de Wilhelm Meister. Programa de Pós-Graduação em Educação. Universidade de Passo Fundo (RS), 2018. 214 p. Tese de Doutorado.

RITTELMEYER, C. Bildende Wirkungen ästhetischer Erfahrungen: wie kann man sie erforschen? [Efeitos formadores das experiências estéticas: como podemos pesquisá-los?] Weinheim (Alemanha): Beltz Juventa, 2016.

SOETEBBER, J. Erkenntnispraxis als umbildende Erfahrung - Goethes Begriff von Selbstbildung [Práxis do conhecimento como experiência remodeladora: o conceito de Goethe de autoformação]. RoSE - Research on Steiner Education, Oslo (Noruega), Vol.7, $\mathrm{n}^{\circ}$ 1, July, 2016. p.14-21. Disponível em: https://www.rosejourn.com/index.php/rose/article/view/330. Acesso em: 05/02/2020.

STEINER, R. Der menschliche und der kosmische Gedanke. [O pensamento humano e cósmico] Dornach (Suíça): Rudolf Steiner Verlag, 1990.

STEINER, R. Arte e estética segundo Goethe: Goethe como inaugurador de uma estética nova. São Paulo: Antroposófica, 1998.

STEINER, R. O método cognitivo de Goethe: linhas básicas para uma gnosiologia da cosmovisão goethiana. São Paulo: Antroposófica, 2004.

STOCKMEYER, E.A.K.. Rudolf Steiner's Curriculum: for Steiner-Waldorf schools: an attemp to summarise his indications. Edinburgh, Escócia: Floris Books, 2015.

TRAUB, H. Ich und Du: Aspekte zu einer Theorie der Interpersonalität in Rudolf Steiners Philosophie der Freiheit [Eu e Tu: aspectos para uma teoria da interpersonalidade na Filosofia da Liberdade de Rudolf Steiner]. Research on Steiner Education (RoSE), Oslo (Noruega), Volume 10, nº1, p.1-20, 2019. Disponível em:

https://www.rosejourn.com/index.php/rose/article/view/498. Acesso em 09/02/2020. 